\title{
MORPHOLOGICAL AND PHYSICOCHEMICAL CHARACTERISATION OF DATE PALM CULTIVARS FROM GHARDAÏA (SOUTHEAST ALGERIA)
}

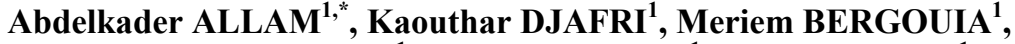 \\ El-Haîfa KHEMISSAT ${ }^{1}$, Mohamed TAMA ${ }^{1}$, Brahim TALEB ${ }^{1}$ \\ `E-mail: allam_aek@yahoo.fr
}

Received: Feb. 11, 2020. Revised: Mar. 16, 2021 Accepted: Mar. 23, 2021. Published online: Mar. 31, 2021

ABSTRACT. The date palm (Phoenix dactylifera L.) is an economically important species vital for food security in Algeria, especially for the southern population. There are an estimated 18 million palm trees in Algeria with more than 1000 cultivars. This poorly known resource is unfortunately threatened with extinction. This work was carried out on 24 date palm cultivars, studying their morphological and physicochemical characteristics, such as the weight, length and diameter of the date and the seed, and the consistency, moisture, $\mathrm{pH}$ and sugar content of the dates. Ten homogeneous palm trees were selected for each cultivar. From each tree, we collected 40 fruits devoid of their calices (4-5 fruits per bunch), at different heights and orientations in each bunch. The results show that the morphological and physicochemical characteristics vary from one cultivar to another. The dates of most cultivars have a combination of good and bad characteristics. The cultivar Tmar-Bousbaa has very high values for the characteristics weight, length, and diameter of the date and seed $(23.16 \mathrm{~g}$, $4.90 \mathrm{~cm}, 2.85 \mathrm{~cm}$, and $1.53 \mathrm{~g}, 2.74 \mathrm{~cm}$, $0.94 \mathrm{~cm}$, respectively). The cultivars Takarnait and Halwa have high acidity, varying between 1.08 and $1.92 \mathrm{~g} / \mathrm{kg}$ of fresh material and a $\mathrm{pH}$ of less than 5.46. The cultivar Bouarous has a low sugar content: less than $63 \%$. Principal component analysis (PCA) was used to analyse the whole dataset, revealing high variability among the cultivars. Thus, out of 14 characteristics investigated, ten have been shown to be strong discriminating factors.

Keywords: characterization; cultivars; date palm; genetic diversity; oasis.

\section{INTRODUCTION}

In Algeria, the culture of dates extends between latitudes of $25^{\circ}$ and $35^{\circ}$ north (Hannachi, 2012). It is distributed in the south-east (Biskra, El-Oued and Ouargla), south-west

\footnotetext{
1 Experimental Station of Sidi Mehdi Touggourt, National Institute of Agronomic Research of Algeria (INRAA) Touggourt B.P 17, Algeria
} 
(Bechar and Adrar), centre-far south (Ghardaia, Tamanrrassat, Tindouf and Illizi) and other sparse areas. However, the most number of the date palm is in the south-east, home to almost $60 \%$ of national heritage of date palms (Merrouchi and Bouammar, 2015).

Algeria has nearly 18.6 million palm trees, ensuring a total production of 1.3 million tonnes of dates, across all varieties (Benziouche, 2017; Belguedj, 2019; Rekis and Laiadi, 2020). The region of Ghardaiia produces nearly 608,000.00 kilograms of dates and supports nearly $1,300,000$ productive palm trees, 524,350 of which are of the Deglet Nour variety. The varieties Ghars, Timjouhart and Bent Kbala are estimated to number 706,560 palm trees (Algerian Ministry of Agriculture and Rural Development, 2018). In this region, the palm is not considered to be the main agriculture, as other crops besides palm trees are also important. In addition, more than $46 \%$ of the dates produced by the different cultivars are of lower quality compared to the most distinguished variety Deglet Nour, and are generally intended for family consumption (Algerian Ministry of Agriculture and Rural Development, 2018).

Concerning the genetic diversity of the palm, the number of cultivars inventoried in Algeria is estimated at more than 1100 , but only a few are commercially important due to the monoculture of the Deglet Nour variety, which accounts for more than $60 \%$ of the total number of palm trees (Hannachi, 2012; Merrouchi and
Bouammar, 2015). Unfortunately, this poorly-known diversity is threatened with disappearance due to environmentally degrading factors, including silting up, lack of water, rural exodus, and monovarietal cultivation. This has regressive effects on varietal diversity in particular, and the fragile oasis ecosystem in general (Hannachi, 2012).

In addition, a serious vascular disease of the date palm known as Bayoud has already resulted in the loss of more than 3 million trees in Algeria. At present, this disease constitutes a permanent threat to the phoenicultural heritage of the region, as measures to tackle it have not been as effective as desired. In the global strategy to fight this disease, the varietal diversity seen in the date palm is a major advantage (Algerian Ministry of Land Management and Environment, 2014).

On the other hand, several constraints limit the development of the date palm cultivation, including the small size of farms and their fragmentation. A high proportion (more than 46\%) of palm trees of the so-called common cultivars do not have great economic interest. The high levels of degradation of palm groves are due to several factors, such as aging, lack of maintenance and poor irrigation systems (MADR, 2018).

As far as the characterisation of date palm cultivars is concerned, little work has been done. Existing work includes that of Harrak et al. (2003) and Djerouni et al. (2015), who studied the morphological variability 
of cultivated male palms from the Oued Righ collection. Simozrag et al. (2016) have evaluated the phenotypic diversity of date palms in the Ziban region, followed by physicochemical characterisation of the main date cultivars by Acourene and Tama (1997) and studies describing 26 cultivars of date palms grown in the same region by Bedjaoui and Benbouza (2018) and Rekis and Laiadi (2020).

The objective of this study is to respond to the lack of knowledge in this field, and characterise the date palm cultivars of the Ghardaïa region in order to protect those with a high food and market value. In addition, the evaluation of the nutritional value of dates will allow them to be more valued industrially and increase the number of cultivars considered to be of interest.

\section{MATERIALS AND METHODS}

\section{Study area}

The study was carried out within the region of Ghardaïa, located $600 \mathrm{~km}$ south of Algiers in the central part of the north of the Algerian Sahara, at the entrance of the desert at $32^{\circ} 30$ north latitude and $3^{\circ} 45$ longitude (Ben Semaoune, 2008). It is located in a moderate winter climate. The region is characterised by an average annual temperature of $22.6^{\circ} \mathrm{C}$, reaching $33.9^{\circ} \mathrm{C}$ at its highest in August and $11.3^{\circ} \mathrm{C}$ at its lowest in January. The temperature variations have a large amplitude. During the day, in summer, the temperature can reach $50^{\circ} \mathrm{C}$ in the shade, but at night, in winter, it can fall below zero. Precipitation is low and irregular, with an annual average rainfall of 63.6 $\mathrm{mm}$ (Chellat, 2014). Agriculture in the study region consists mainly of date palms with various intercropping crops, such as fruit trees and other plant species (Khene, 2013).

\section{Vegetal material}

Date samples were taken from 24 date palm cultivars in the Ghardaia region.

\section{Methods}

\section{Methodological approach}

The approach used was based on two essential phases:

a. The survey and identification phase: during this phase, the sampling areas were identified according to their geographic location, age, and the importance of the genetic diversity of the date palm.

b. The global sampling phase: this phase was carried out before and during the maturation of the fruits (dates). We sampled only cultivars with local appellations, selected by palm trees farmers, and which have been propagated vegetatively (Food and Agriculture Organization of the United Nations, 1990).

\section{Sampling method}

The followed sampling method is recommended by International Plant Genetic Ressources Institue (2005) and Rekis et al. (2020). Three homogeneous palm trees from each cultivar were chosen. Per palm, we took 40 fruits devoid of their chalices (4 - 5 fruits per cluster), at various heights and orientations of palms. Date fruits were harvested at a mature stage (Acourene and Tama, 1997; International Plant Genetic Ressources Institue, 2005).

\section{Analytical methods}

Physical analysis

The colour was evaluated using a colour chart and the consistency was determined by touch. The weight and size were measured from a sample of ten dates 


\section{MORPHOLOGICAL AND PHYSICOCHEMICAL CHARACTERISATION OF DATE PALM CULTIVARS}

taken at random from a total of $40-60$ date fruits per cultivar. The fresh weight of the date, seed, and pulp were determined for each variety using an analytical balance (Sartorius CP225D). The length and width of the date and the seed of each variety were measured using calipers (Acourene and Tama, 1997).

\section{Biochemical analysis of dates}

The moisture content was determined by drying $10 \mathrm{~g}$ of dates in an oven at $105^{\circ} \mathrm{C}$ for 24 hours. The ash content was determined by incineration of $1 \mathrm{~g}$ of date in a muffle furnace at a temperature of $600{ }^{\circ} \mathrm{C}$ for 3 hours (Association of Analytical Communities, 1970). The $\mathrm{pH}$, reducing sugars, sucrose and total sugars were determined according to previously described methods (Audigie et al., 1984).

\section{Date quality assessment}

- Morphological evaluation criteria

According to FAO (1990), morphological analyses were focused on the most discriminating characteristics, namely: weight of date (DW); weight of pulp (PW); length of date (DL); diameter of date (DD) and consistency (CD); weight of seed (SW); length of seed (SL) and diameter of seed (SD); weight ratio between seeds and fruits (SW/DW).

- Physicochemical evaluation criteria

The criteria for qualitative evaluation of dates have been reported by Meligi and Sourial (1982) and Mohammed et al. (1983) on Egyptian and Iraqi cultivars (Table 1).

- Statistical analysis

The results obtained were analysed using the programme XLSTAT (Addinsoft, XLSTAT.2020.1.3), using principal component analysis (PCA). According to Philippau (1986), PCA is an essentially descriptive statistical method. Its objective is to present, in a graphical form, the maximum of descriptive characters contained in a data table.

\section{RESULTS}

In order to assess the physical and biochemical quality of the dates of different cultivars, we have taken into account the standards set by the Ministry of Agriculture in the interministerial decree of 17 November 1992 for the common varieties, as well as the quality standards applied in the international scale reported by Meligi and Sourial (1982).

Thus, a date is said to be of acceptable physical and biochemical quality when it presents: no anomalies and not damaged; date weight $\geq$ greater than or equal to $6.5 \mathrm{~g}$; pulp weight $\geq 5.5 \mathrm{~g}$; length $\geq 3.5 \mathrm{~cm}$; diameter $\geq 1.5 \mathrm{~cm} ; \mathrm{pH} \geq 5$; moisture content of $10-30 \%$; sugar content $\geq$ $65 \%$.

\section{Evaluation of the morphological characteristics of the date}

The results in Table 2 show that the morphological characteristics of the fruits vary from one cultivar to another. The cultivar Tmar-Bousbaa (TamB) has very high values for the characteristics: weight of the date (DW), weight of the pulp (PW), length and diameter of the date (LD and DD). These values were $23.16 \mathrm{~g}$, $21.63 \mathrm{~g}, 4.90 \mathrm{~cm}$ and $2.85 \mathrm{~cm}$, respectively. On the other hand, the cultivars, Tadmamt (Tad) and Amadjoudja (Amd) are characterised by low date weight (DW), pulp weight (PW), and length and the 


\section{A. ALLAM, K. DJAFRI, M. BERGOUIA, E.H. KHEMISSAT, M. TAMA, B. TALEB}

diameter of the date (LD and DD). These values were 5.62 and $5.81 \mathrm{~g}$, 4.60 and $4.99 \mathrm{~g}, 3.69$ and $3.06 \mathrm{~cm}$, and 1.76 and $1.83 \mathrm{~cm}$, respectively.

Concerning the morphological characteristics of the seed, the cultivar (TamB) has high weight (SW), length (SL) and diameter (SD): $1.53 \mathrm{~g}, 2.74$ $\mathrm{cm}$ and $0.94 \mathrm{~cm}$, respectively. On the other hand, the cultivars Takarnait (Tak), Dguel-Djedir (DgJd) and

Bouarous (Brs) have low weight, length and diameter of the seed: 0.65 and $0.83 \mathrm{~g}, 2.16$ and $2.43 \mathrm{~cm}$, and 0.71 and $0.76 \mathrm{~cm}$, respectively. Based on their consistency, these cultivars can be subdivided into three groups, soft, semi-soft and dry.

Concerning the morphological characteristics of the seed, the cultivar Tmar-Bousbaa (TamB) has high weight (SW).

Table 1 - Qualitative characteristics of dates and their description (according to Meligi and Sourial, 1982; Mohammed et al., 1983)

\begin{tabular}{|c|c|c|c|c|}
\hline Characteristic & Symbol & Evaluation & Standards & Appreciation \\
\hline \multirow{3}{*}{ Date weight (g) } & \multirow{3}{*}{ DW } & Low & $<6.5$ & Bad character \\
\hline & & Medium & $6.5-8.5$ & Acceptable \\
\hline & & High & $>8.5$ & Good character \\
\hline \multirow{3}{*}{ Pulp weight (g) } & \multirow{3}{*}{ PW } & Low & $<5.5$ & Bad character \\
\hline & & Medium & $5.5-7.5$ & Acceptable \\
\hline & & High & $>7.5$ & Good character \\
\hline \multirow{3}{*}{$\begin{array}{l}\text { Seed weight/Date } \\
\text { weight }(\%)\end{array}$} & \multirow{3}{*}{ SW/DW } & Low & $<10$ & Good character \\
\hline & & Medium & $10-18$ & Acceptable \\
\hline & & High & $>18$ & Bad character \\
\hline \multirow{3}{*}{ Date length $(\mathrm{cm})$} & \multirow{3}{*}{ DL } & Reduced & $<3.5$ & Bad character \\
\hline & & Medium & $3.5-4$ & Acceptable \\
\hline & & Long & $>4$ & Good character \\
\hline \multirow{3}{*}{ Date diameter $(\mathrm{cm})$} & \multirow{3}{*}{ DD } & Low & $<1.5$ & Bad character \\
\hline & & Medium & $1.5-1.8$ & Acceptable \\
\hline & & High & $>1.8$ & Good character \\
\hline \multirow{3}{*}{ Moisture (\%) } & \multirow{3}{*}{$\mathrm{H}$} & Medium & $10-25$ & Good character \\
\hline & & High & $25-30$ & Acceptable \\
\hline & & Very high & $>30$ & Bad character \\
\hline \multirow{3}{*}{ Total sugars (\%) } & \multirow{3}{*}{ ST } & Low & $<65$ & Bad character \\
\hline & & Medium & $65-75$ & Acceptable \\
\hline & & High & $>75$ & Good character \\
\hline $\mathrm{pH}$ & $\mathrm{pH}$ & & $\leq 5$ & $\begin{array}{l}\text { Acidic (bad } \\
\text { character) }\end{array}$ \\
\hline
\end{tabular}

Evaluation of the physicochemical characteristics of the date

The cultivars of soft and semi-soft consistency have high moisture (Table 2). On the other hand, cultivars with a dry consistency have low moisture. In terms of acidity, the results obtained show that the cultivars, Tinaceur (Tinc), Takarnaït (Tak) and Halwa (Hal) have a high 
acidity, varying between 1.08 and $1.92 \mathrm{~g} / \mathrm{kg}$ of fresh material (FM), and a pH between 4.94 and 5.46.

Cultivars with a soft consistency are rich in reducing sugars (SR) but poor in sucrose. On the other hand, cultivars of dry and semi-soft consistency contain similar amounts of sucrose and reducing sugars (SR). Similar results have been reported by Yousif et al. (1982), Sawaya et al. (1983), Baangoud and Shamshad (1984), Bin-Shahna et al. (1987), Acourene and Tama (1997) and Acourene et al. (2001), on different date cultivars from other phoenicultural countries. Finally, the cultivar Tassebaiit (Tsbt) has a very high total sugar content, greater than $88 \%$. On the other hand, the cultivar Bouarous (Brs) has a low sugar content, less than $63 \%$. In general, the majority of cultivars studied have a relatively satisfactory total sugar (TS) content, greater than $70 \%$.

\section{Technical evaluation of the date}

Our analysis (Table 2) shows that most of the cultivars studied have a combination of good and bad traits. The fruit of the cultivars AliOurached (AlOu), Dguel-Djedir (DgJd), and Ghars (Ghr) has good morphological and biochemical characteristics, characterised by: $8.47 \mathrm{~g}<$ high date weight $<15.68 \mathrm{~g}$; $4.15 \mathrm{~cm}<$ high date length $<4.26 \mathrm{~cm}$; $1.80 \mathrm{~cm}<$ large date diameter < $2.42 \mathrm{~cm} ; 25.7 \%<$ a moisture between $<31.2 \%$; a high to very high total sugar content $>68.5 \%$.

However, the fruit of cultivars including Baba-Kassi (BKs) and
Bent-Kbala (BKb) has good morphological and biochemical characteristics, but very high moisture, greater than $37 \%$. This makes their preservation difficult and, consequently, also their packaging and marketing. In addition, the fruit of cultivars including Akerbouch (Akr), Amadjouja (Amd), Azerza (Azr), and Dguel-Latrech (DL) has a high to very high sugar content (79.30-68.82\%) and an acceptable moisture (27.8$30.2 \%$ ), but a low to medium weight, length and diameter (5.81-13.33 g; $3.06-5.35 \mathrm{~cm} ; 1.70-2.46 \mathrm{~cm}$ ). For these cultivars, the application of particular cultivation techniques (sufficient and regular irrigation, fertilisation, limitation of the number of bunches and chiseling) can improve the characteristics of their fruits. On the other hand, the fruit of the cultivars, Aguema-N'djennet $(\mathrm{AgNj}), \quad$ Dguel-Latrech (DL), Guachouche (Gch), Takarnaï (Tak) and Tibenboul (Tbl) has poor characteristics, which makes their use and marketing difficult. Finally, the results obtained show that the fruit of the cultivars Ali-Ourached (AlOu), Dguel-Djedir (DgJd) and Tinaceur (Tinc) has a similar or better physical and biochemical quality to that of the most commercialised and appreciated varieties, such as Deglet-Nour, Ghars, Mech-Degla and Degla-Beida. We note that the fruit of the dry cultivar Tinaceur (Tinc) has physical and biochemical characteristics similar to those of Degla-Beida and Mech-Degla (Acourene et al., 2001). 


\section{A. ALLAM, K. DJAFRI, M. BERGOUIA, E.H. KHEMISSAT, M. TAMA, B. TALEB}

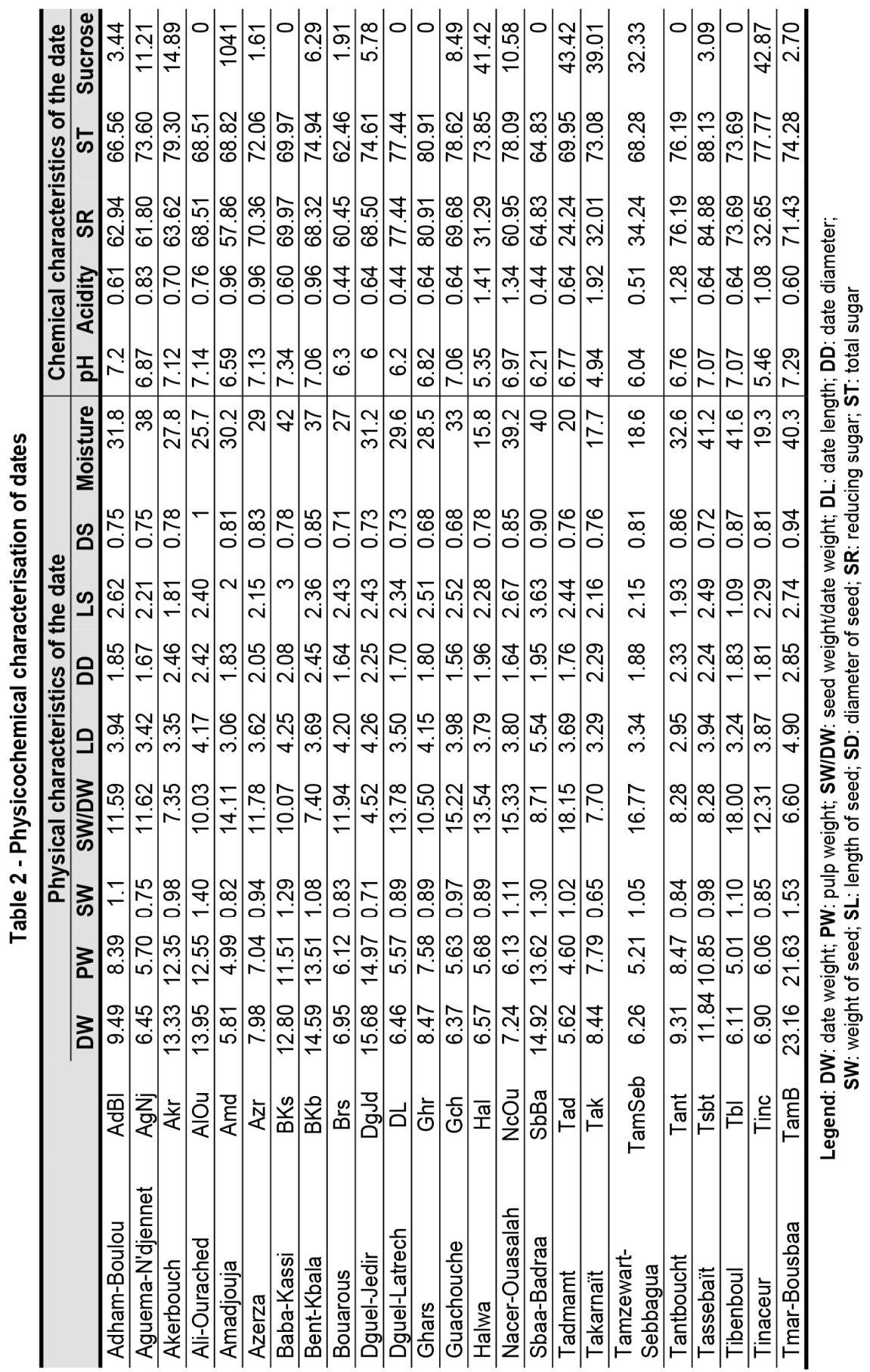




\section{MORPHOLOGICAL AND PHYSICOCHEMICAL CHARACTERISATION OF DATE PALM CULTIVARS}

Similarly, the fruit of the soft cultivars Ali-Ourached (AlOu) and Dguel-Djedir (DgJd) has better physical and chemical characteristics compared to the variety Ghars (Ghr). In addition to these qualitative factors defining the quality of the date, there are also subjective factors, such as colour and taste. In general, yellow, white or brown cultivars are more appreciated by consumers; however, the taste differs from one consumer to another.

\section{Evaluation of technical aptitudes of different cultivars}

The date has long been considered the staple food of the Saharan populations. According to Table 2, most of the cultivars studied have an acceptable nutritional value (rich in sugars). However, the cultivars Aguema-N'djennet $(\mathrm{AgNj})$, Dguel-Latrech (DL), Guachouche (Gch), Takarnaït (Tak) and Tibenboul (Tbl) have a poor nutritional value. These are generally used in animal feed. In addition, the fruit of other cultivars such as Akerbouch (Akr), Amadjouja (Amd), Azerza (Azr), and Dguel-Latrech (DL), despite their richness in sugars, have poor morphological characteristics.

Therefore, these cultivars can be used as raw material for making syrups, alcohols, vinegar and citric acid. On the other hand, some soft cultivars that are rich in sugars can easily be used to manufacture date paste, which is very popular locally and can be incorporated in the manufacture of cakes. However, currently only the dates produced by the two cultivars Ghars (Ghr) and Tantboucht (Tant) are used for making date paste.

\section{Correlation matrix}

The correlation matrix reveals several correlations between the studied characteristics (Table 3). Positive correlations were observed between the weight of the date (DW), the weight of the pulp (PW), the weight of the seed (SW), the length of the date (DL) and the diameter of the date (DD). Likewise, a positive correlation between the moisture, the $\mathrm{pH}$ and the reducing sugar content (RS) was observed.

However, negative correlations between $\mathrm{pH}$ and acidity; moisture and sucrose content; $\mathrm{pH}$ and sucrose content; and sucrose content and the reducing sugar content were noted. This shows that dates with a high moisture are rich in reducing sugars and have a neutral to basic $\mathrm{pH}$, but are poorly supplied with sucrose. On the other hand, dates of dry consistency have low moisture, a slightly acidic $\mathrm{pH}$ and a high sucrose content.

\section{Classification of the different cultivars according to principal component analysis}

Principal component analysis (ACP) was carried out on 14 characteristics of the fruit and the seed. The results obtained show that the two axes (Fig. 1) contribute $37.87 \%$ (axis 1) and $16.29 \%$ (axis 2) of the total inertia, a cumulative percentage of $54.17 \%$. This indicated that axis 1 contains the majority of the exploitable information. 


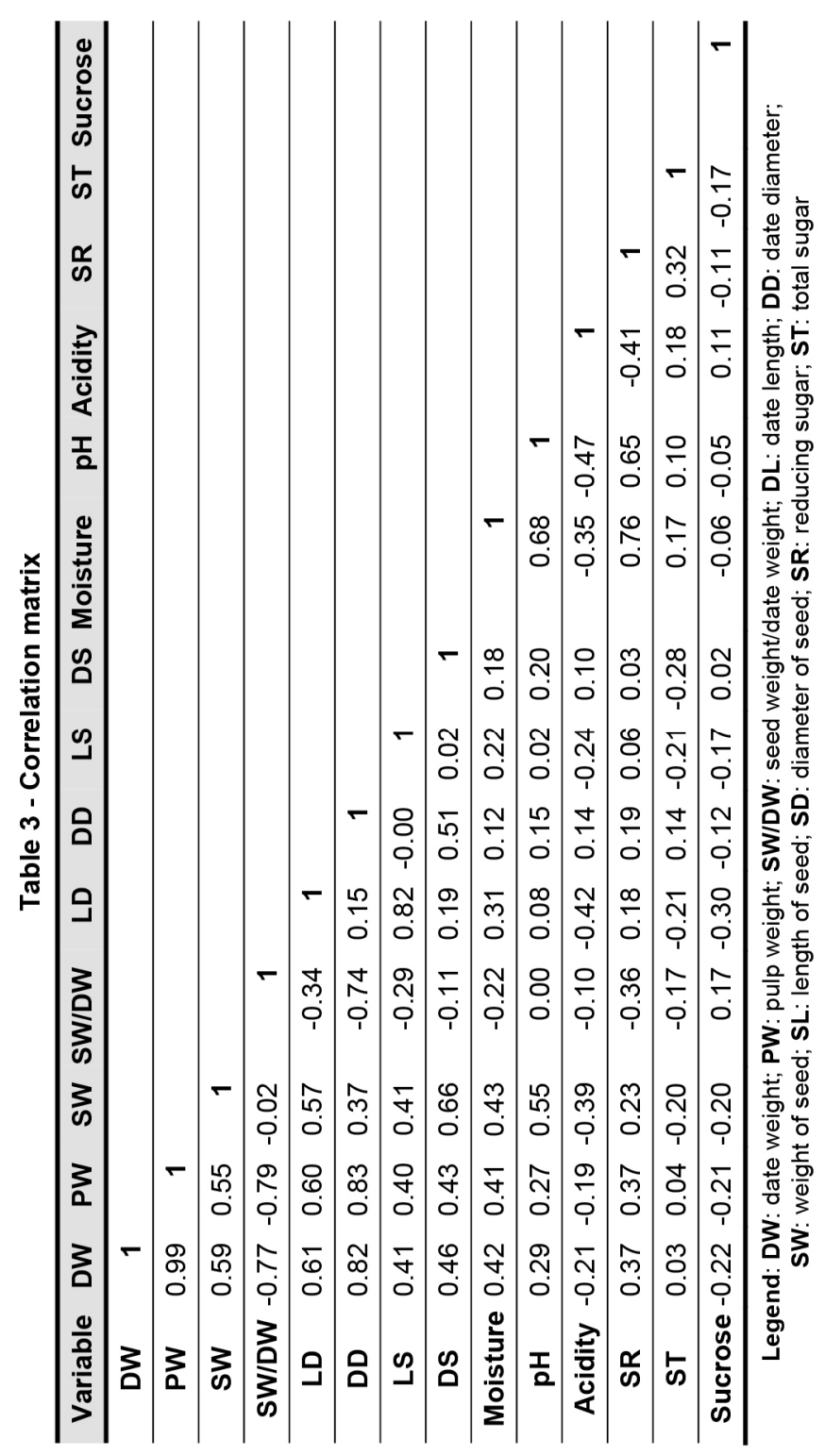

Moreover, in principal component analysis, for a given trait to contribute to the explanation of variation on axes 1 and 2, its squared correlation must be high. For this purpose, out of the
14 characteristics of the date and the seed studied, ten are discriminating, namely: date weight (DW), pulp weight (PW), seed weight (SW), seed to fruit weight ratio (SW/DW), date 
length (DL), date diameter (DD), moisture, $\mathrm{pH}$, acidity and reducing sugar content (SR). In addition, the cloud of samples projected on axis 1 and axis 2 shows appreciable differences between the different cultivars. In fact, the further the individuals are from the centre of the plane, the more dissimilar they are, and if they are close to the centre it indicates that they have common characteristics. Thus, the dispersion of the cultivars studied on the plane indicates that there is high variability among them. According to Fig. 1, a first classification of the cultivars can be carried out. For this purpose, these cultivars can be subdivided into four groups.

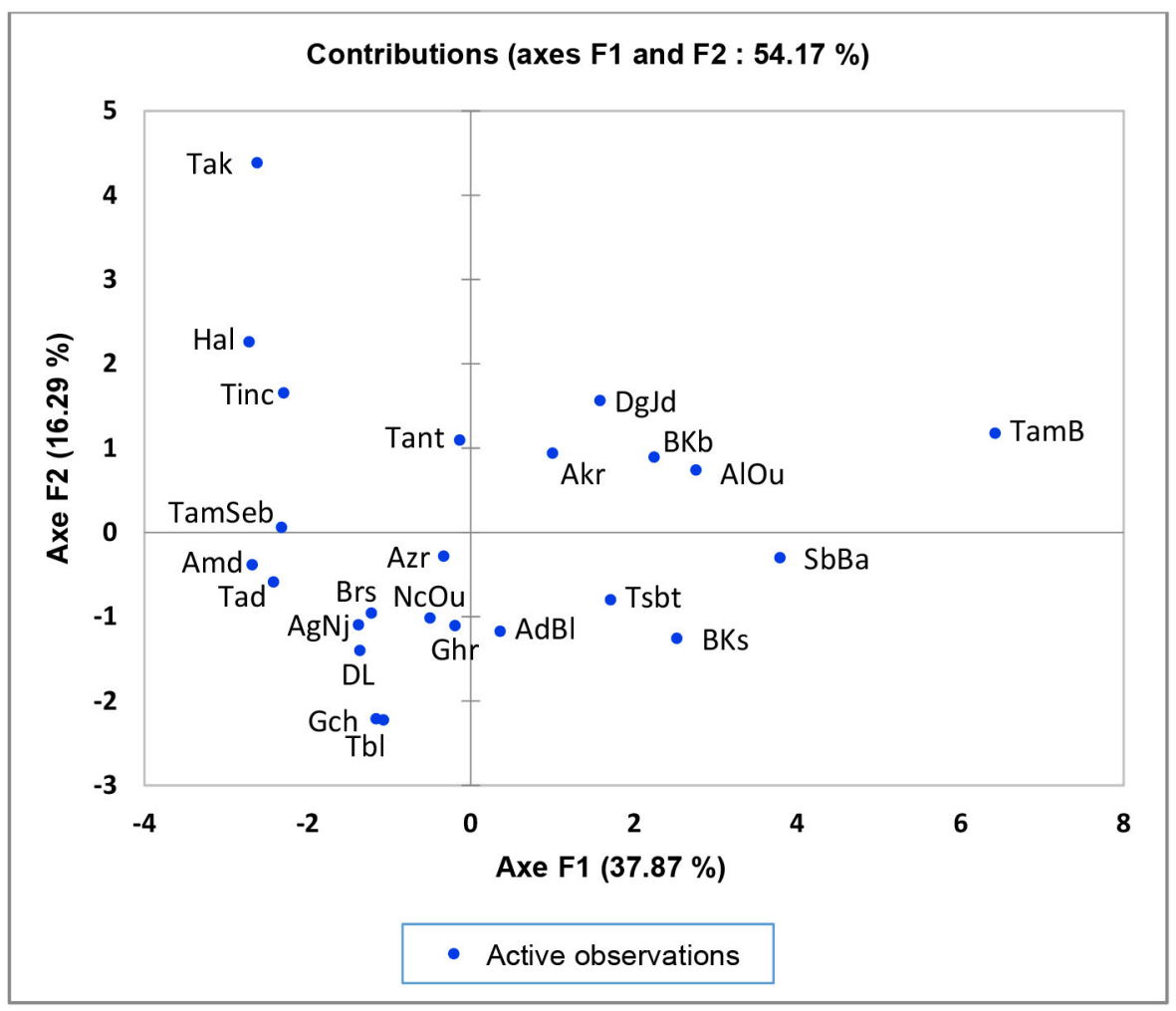

Figure 1: Presentation cultivars according to F1 and F2 plan

Note: Active observations - date palm cultivars that are used in principal component analysis (ACP)

Legends: Cultivar names

AdBI: Adham-Boulou; AgNj: Aguema-N'djennet; Akr: Akerbouch; AlOu: Ali-Ourached;

Amd: Amadjouja; Azr: Azerza; BKs: Baba-Kassi; BKb: Bent-Kbala; Brs: Bouarous;

DgJd: Dguel-Jedir; DL: Dguel-Latrech; Ghr: Ghars; Gch: Guachouche; Hal: Halwa; NcOu: Nacer-Ouasalah; SbBa: Sbaa-Badraa; Tad: Tadmamt; Tak: Takarnaït;

TamSeb: Tamzewart-Sebbagua; Tant: Tantboucht; Tsbt: Tassebaït; Tbl: Tibenboul;

Tinc: Tinaceur; TamB: Tmar-Bousbaa. 
Group 1: cultivars with a high moisture $(\geq 41.2 \%)$; a neutral $\mathrm{pH}$ (7.07-7.34); and a high reducing sugar content $(\geq 69.97 \%$ ). This group consists of the cultivars Baba-Kassi (BKs) and Tassebaït (Tsbt).

Group 2: cultivars with a low date and pulp weight $(\leq 6.45 \mathrm{~g}$ and $\leq$ $5.70 \mathrm{~g}$, respectively); a high seed to fruit weight ratio $(>11.62)$; a small date diameter $(<1.83 \mathrm{~cm})$; a high moisture (>33\%); a slightly alkaline $\mathrm{pH}(>6.87)$, and an average reducing sugar content between 61.80 and $73.69 \%$. This group consists of the cultivars Aguema-N'djennet $(\mathrm{AgNj})$, Guachouche (Gch) and Tibenboul (Tbl).

Group 3: cultivars with a low date and pulp weight $(\leq 6.90 \mathrm{~g}$ and $\leq$ $6.12 \mathrm{~g}$, respectively); a high to very high seed to fruit weight ratio $(\geq$ $11.94 \%)$; a small date diameter $(\leq$ $1.96 \mathrm{~cm}$ ); a low to medium moisture (15.8-30.2\%), and a low to medium reducing sugar content (24.24$57.86 \%$ of the dry matter). This group consists of the cultivars Amadjoudja (Amd), Halwa (Hal), Tadmamt (Tad), Bouarous (Brs) and Tinaceur (Tinc).

Group 4: cultivars with medium to high date and pulp weight (13.95$15.68 \mathrm{~g}$ and 12.55-14.97 g, respectively); a low seed to date weight ratio $(<10.03)$; a large date diameter $(>1.95 \mathrm{~cm})$; a medium to high moisture (25.7-40\%); a neutral $\mathrm{pH}$ (6-7.14), and a high reducing sugar content $(>64.83 \%)$. This group consists of the cultivars Ali-Ourached (AlOu), Dguel-Djedir (DgJd) and Sbaa-Badraa (SbBa).
The fruit of the other cultivars has intermediate physical and chemical characteristics, with no discriminating characteristics.

\section{CONCLUSION}

The preservation of phoenicultural resources at the regional level, particularly those threatened with genetic erosion, is an urgent priority. In the region of Ghardaïa, there are a total of 114 cultivars. They are distinguished using various characteristics, which determine the interest of date growers towards them.

In this study, the evaluation of the quality of the dates revealed that the majority of the fruits of the cultivars of this region possess a combination of good and bad characteristics, which affect their suitability for either consumption or processing. Nevertheless, the dates produced by the cultivars AliOurached (AlOu) and Dguel-Djedir (DgJd) have similar properties to those of the cultivars Deglet-Nour, Ghars, Mech-Degla and Degla-Beida. These varieties have high commercial value due to the large size and weight of the fruit. Consequently, their marginalisation is unnecessary, as they belong to our phoenicultural heritage, we must protect this heritage and aim to widen its genetic diversity.

The evaluation and description of the morphological and biochemical characteristics of the fruits of these cultivars revealed variation between cultivars. These differences are due to 
the genetic diversity (heterozygosity) of the date palm and/or to the growing conditions.

Funding: This work was supported by the Algerian Ministry of Agriculture and Rural Development under a grant from the National Research Fund.

\section{REFERENCES}

Acourene, S. \& Tama, M. (1997). Physical and Biochemical characterization of main date palm fruits cultivars of the region of Zibans. J. Recherche Agronomique, Ed. INRAA, 1: 59-66.

Acourene, S., Belguedj,M., Tama, M. \& Taleb, B. (2001).Characterization, evaluation of date quality and identification of rare date palm cultivars from the Biskra region. J. Recherche Agronomique, Ed. INRAA, 8: 19-39.

Agricultural Services Directorate (DSA) (2018). Agricultural statistics. Ghardaia, Algeria.

Association of analytical communities (AOAC) (1970). Official methods of analysis. Washington. Ed. Itth.

Audigie, C.I., Figarella, J. \& Zonszani F. (1984). Manipulation of biochemical analyzes. Doin éditeurs, 1ère édition, Paris, France.

Baangoud, S.M. \& Shamshad, M.A. (1984). Chemical composition of major dates cultivars in the united Arab Emirates. Date palm Journal; 3(2): 381-394.

Belguedj, M. (2019). Date sector, price and margin formationof la DegletNour. J. Recherche Agronomique, Ed. INRAA, 18(1): 57-65.

Ben Semaoune, Y. (2008). Saharan grazing in the new spatial dynamics: contribution to the establishment of a spatial planning and management plan (S.A.G.E.) - case of the Ghardaïa region. Thesis for MSc.
University KasdiMerbah of Ouargla, Algeria.

Benziouche, S.E. (2017). Biological agriculture, a development tool for the date sector in the Ziban region of Algeria. J. Cah. Agric., 26: 1-8.

Bin-Shahna, S. Qassim, Y.A. \& AlQahri, M. (1987). The chemical composition of various types of dates in the P.D.R.Y. J. Date Palm, 5(2): 143-195.

Chellat, S. (2014). Sedimentological and paleoenvironmental framework of the Mio-Pliocene Formations of the Guerrara Region (Ghardaïa). Thesis for PhD. University of Constantine, Algeria.

Djerouni, A., Chala, A., Simozrag, A., Benmhaia, R. \& Baka, M. (2015). Evaluation of male palms used in pollination and the extent of its relationship with cultivars of datepalms (Phoenix dactylifera L.) grown in region of OuedRigh, Algeria. $J$. Pakistan Journal of Botany, 47: 2295-2300.

Ozrag, A., Chala, A., Djerouni, A. \& Elmoncef Bentchikou, M. (2016). Phenotypic diversity of date palm cultivars (Phoenix dactylifera L.) from Algeria. Gayana. Botánica, 73(1), 42-53. DOI: 10.4067/s071766432016000100006

Food and Agriculture Organization of the United Nations (FAO) (1990). Maghrebian workshop on prospecting methodology. Edit. U.R.Z.A. El-Goléa, Algeria.

Hannachi, S. (2012). Date palm genetic resources (Phoenix dactylifera L.) in Algeria: Analysis of inter and intra variability of the main cultivars. Thesis for MSc. National School of Agronomy (ENSA) of ElHarrach, Algeria ( $\mathrm{Fr})$.

Harrak, H., Boujnah, M. \& Hamouda, A. (2003). Physical and morphological characterizations of the main varieties of Moroccan dates, 107: 5 76.

International Plant Genetic Ressources Institue (IPGRI) (2005). Date palm 


\section{A. ALLAM, K. DJAFRI, M. BERGOUIA, E.H. KHEMISSAT, M. TAMA, B. TALEB}

descriptor (Phoenix dactylifera L.). Rome, Italy.

Khene, B. (2013). Dynamics of phoenicultural production systems and promotion of the "date" sector: development prospects - Case of the Ghardaïa region. Thesis for PhD. University KasdiMerbah of Ouargla, Algeria.

Meligi, M.A. \& Sourial, G.F. (1982). Fruit quality and general evaluation of some Iraqi date palm cultivars grown under conditions of barrage region: Proceedings of the first symposium on the date palm conference (pp. 212 - 220), Saudi-Arabia.

Merrouchi, L. \& Bouammar, B. (2015). The functioning of the date's sector in Touggourt Southeast Algerian region. J. El-Bahith Review, 15: 201211.

Ministry of Agriculture and Rural Development (MADR) (2018). Agricultural statistics. Algeria.

Ministry of Spatial Planning and the Environment (MATE) (2014). 5th National Report on the implementation of the Convention on Biological Diversity at the national level, Algeria.

Mohammed, S., Shabana, H.R. \& Mawloud, E.A. (1983). Evaluation and identifications of Iraqi date cultivars: Fruit

Philippau, G. (1986). How to interpret the results of a principal component analysis? Technical Institute of Cereals and Forages (ITCF). Statistical Studies Service. Paris, France.

Rekis, A. \& Laiadi, Z. (2020). Interrelationships between some vegetative components and fruit quality of Algerian date palm. J. Agricultural Science and Technology, 12(1): 77-81.

Rekis, A., Laiadi, Z. \& Mehenni, M. (2020). Morphological characteristics denomination of date palm studied cultivars. Algerian Journal of Arid Regions (JARA), 14 (1). Scientific and Technical Research Centre for Arid Areas (CRSTRA), Algeria, 131140.

Sawaya, W.N., Safi, L., Black, L.T. \& AlMuhamed, M.M. (1983). Physical and chemical characterization of the major date varieties grown in SaudiArabia. J. Date Palm, 2 (2): 183-196

Simozrag, A., Chala, A., Djerouni, A. \& Elmoncef Bentchikou, M. (2016). Phenotypic diversity of date palm cultivars (Phoenix dactylifera L.) from Algeria. J. Gayana Botánica, 73: 42-53.

Yousif, A.K., Benjamin, N. \& Dand Kado, A. (1982). Chemical composition of four Iraqi date cultivars. J. Date palm, 1(2): 285294. 